\title{
Rheological and fibrinolytic findings in multiple sclerosis
}

\author{
A BRUNETTI, + G L RICCHIERI, $\dagger$ G M PATRASSI,* A GIROLAMI, ${ }^{*}$ AND \\ B TAVOLATO $†$
}

From the Institute of Semeiotica Medica, ${ }^{*}$ and the Department of Neurology and Psychiatry, $\uparrow$ University of Padua Medical School, Padua, Italy

S UMMARY Blood viscosity indices, fibrinolytic activity and other serum proteins related to haemocoagulation have been studied in 36 patients with multiple sclerosis. The whole blood viscosity was found to be increased in multiple sclerosis. The increase was caused by a decrease in erythrocyte deformability since plasma viscosity and haematocrit were normal. Plasminogen, fibrinogen and $\alpha \mathrm{l}$ antitrypsin levels were found to be lower than normal. Such alteratons were not observed in a group of patients with other non-immunological neurological diseases. In the latter group some coagulation indices were even higher than normal. The higher mean age of the pathological controls could explain the observed levels. The abnormalities observed in multiple sclerosis patients are considered to be a consequence of a non-specific activation of the coagulattve system in a chronic immunological disease.

The elevated frequency of an IgG increase in multiple sclerosis (MS) cerebrospinal fluid (CSF) has stimulated several workers to careful estimations of IgG in the serum of MS patients. Little attention has been paid to other (non Ig) serum proteins. ${ }^{1}$ The most constant data are concerned with complement activity and complement factors $^{2}$ and with the coagulation system. Menon et al found an increase of fibrinolytic activity in MS serum, which suggested the possibility of an alteration of the coagulative system. ${ }^{3}$ Such a possibility also was evaluated by Caspary et $a l,{ }^{4}$ who reported an increase of the platelet stickiness in MS. The increased platelet adhesiveness also was found to be correlated to disease activity and to adrenocorticotrophic therapy. ${ }^{5}{ }^{6}$ The alteration of the coagulative system has even been considered to be directly or indirectly related to plaque pathogenesis. ${ }^{7}$ We report the results obtained in a study of the blood viscosity indices, fibrinolytic activity and other serum proteins concerned in coagulation in 36 patients with MS. The results obtained were compared with a normal group and a group of patients with various non-immunological neurological diseases.

$\ddagger$ Deceased.

Address for reprint requests: Dr B Tavolato, Neurology Dept, University of Padua Medical School, 35100-Padua, Italy.

Accepted 21 January 1981

\section{Material and methods}

\section{Patients and controls}

Thirty-six patients affected by "probable MS"8 were evaluated. Twelve were male and 25 were female, with a mean age of 32 years (range 19-66). All these patients were in hospital and were chronic cases with symptoms of a recent relapse or gradual worsening. All received corticosteroids or ACTH during the six months preceding evaluation. Twelve inpatients (two male, 10 female) were taken as pathological controls. They suffered from parkinsonism (2), epilepsy (2), presenile dementia (2), cerebrovascular disease (3), amyotrophic lateral sclerosis (1) sciatic pain (2). The mean age of this group was 54 years (range 45-64). Thirty normal subjects (10 male and 20 female) with a mean age of 34 years (range 25-45) were taken as normal controls.

Measurements were made of whole blood and plasma viscosity, haematocrit $(\mathrm{Ht})$, fibrinogen, plasminogen, euglobulin lysis time (ELT), antithrombin III (AT III), $a 1$ antitrypsin (a1-AT).

Whole blood and plasma viscosity were evaluated in EDTA anticoagulated blood $(1 \mathrm{mg} / \mathrm{ml})$ in a Wells Brookfield LVT cone-plate viscometer (Brookfield Labs, Stoughton, Mass, USA) according to the method proposed by Wells et al. ${ }^{9}$ Aliquots of $2 \mathrm{ml}$ of whole blood and plasma were used in each instance; the test was carried out in duplicate and the average value was used. Blood and plasma viscosity were evaluated at $37^{\circ} \mathrm{C}$. This temperature was constantly maintained by means of a thermostatic pump (Colora, model $\mathrm{N}$ ) supplied by Brookfield Labs. Readings were carried out in every instance after a $30 \mathrm{~s}$ stabilisation period at speed 60 which corresponds to 
$230 \mathrm{~s}^{-1}$ shear rate. Relative viscosity was calculated by the ratio between whole blood viscosity and plasma viscosity as obtained at $230 \mathrm{~s}^{-1}$. For the other tests blood was drawn into plastic syringes containing $3.8 \%$ sodium citrate ( $1 \mathrm{ml}$ of anticoagulant for $9 \mathrm{ml}$ of blood). The blood was then placed in plastic tubes which were centrifuged at $1.000 \mathrm{~g}$ for $15 \mathrm{~min}$. After centrifugation the plasma was separated and then frozen at $-20^{\circ} \mathrm{C}$. All tests were done within 10 days of sample collection.

Haematocrit values were carried out according to standard procedures. For the assessment of plasma fibrinolytic activity we used the Euglobulin Lysis Time according to the method proposed by Cliffton et al. ${ }^{10}$

Fibrinogen, plasminogen, AT III and $a 1-\mathrm{AT}$ were evaluated using single radial immunodiffusion test (M-Partigen, Behringwerke Labs) according to Mancini's method. ${ }^{11}$ For statistical evaluation we used the " $t$ " and the Fisher's exact test.

Table 1 Mean SD and statistical variance analysis of the rheological indices in the normal group compared to the MS group

\begin{tabular}{lccll}
\hline & Mean & $S D$ & $F$ & $p$ \\
\hline $\begin{array}{l}\text { Whole blood } \\
\text { viscosity in cps }\end{array}$ & & & & \\
$\begin{array}{l}\text { MS } \\
\text { Normals }\end{array}$ & 4.59 & 0.51 & - & - \\
$\begin{array}{l}\text { Plasma viscosity } \\
\text { in cps }\end{array}$ & & 0.28 & 3.97 & $<0.05$ \\
$\begin{array}{l}\text { MS } \\
\text { Normals }\end{array}$ & 1.51 & 0.27 & - & - \\
$\begin{array}{l}\text { Relative viscosity } \\
\text { MS }\end{array}$ & 1.51 & 0.10 & 0.01 & NS \\
Normals & 3.09 & 0.27 & - & \\
Haematocrit \% & 2.85 & 0.02 & 5.87 & $<0.05$ \\
MS & & & & \\
Normals & 42.08 & 3.68 & - & - \\
\hline
\end{tabular}

Table 2 Mean SD and statistical variance analysis of the fibrinolytic and serum proteins indices in the normal and in the pathological controls compared to the MS group

\begin{tabular}{|c|c|c|c|c|}
\hline & Mean & $S D$ & $F$ & $p$ \\
\hline $\begin{array}{l}\text { Fibrinolysis in hours } \\
\text { MS } \\
\text { Normals }\end{array}$ & $\begin{array}{l}19 \cdot 08 \\
21 \cdot 46\end{array}$ & $\begin{array}{l}8 \cdot 72 \\
5 \cdot 21\end{array}$ & $-\overline{1} \cdot 72$ & $\overline{\mathrm{NS}}$ \\
\hline $\begin{array}{l}\text { Fibrinogen in } \mathrm{mg} \% \\
\text { MS } \\
\text { Norma!s } \\
\text { Pathological controls }\end{array}$ & $\begin{array}{l}302 \cdot 94 \\
342 \cdot 00 \\
431 \cdot 66\end{array}$ & $\begin{array}{l}98 \cdot 30 \\
49 \cdot 64 \\
53 \cdot 96\end{array}$ & $\begin{array}{r}- \\
3 \cdot 89 \\
18 \cdot 67\end{array}$ & $\begin{array}{l}- \\
<0.05 \\
<0.005\end{array}$ \\
\hline $\begin{array}{l}\text { Plasminogen in } \mathrm{mg} \% \\
\text { MS } \\
\text { Norn:als } \\
\text { Pathological controls }\end{array}$ & $\begin{array}{r}9 \cdot 80 \\
11 \cdot 57 \\
16 \cdot 61\end{array}$ & $\begin{array}{l}2 \cdot 67 \\
1 \cdot 75 \\
5 \cdot 31\end{array}$ & $\begin{array}{l}\overline{12} \cdot 45 \\
39 \cdot 58\end{array}$ & $\begin{array}{l}- \\
<0.005 \\
<0.005\end{array}$ \\
\hline $\begin{array}{l}\text { AT IJI in } \mathrm{mg} \% \\
\text { MS } \\
\text { Normals } \\
\text { Pathological controls }\end{array}$ & $\begin{array}{l}28 \cdot 91 \\
28 \cdot 86 \\
34 \cdot 81\end{array}$ & $\begin{array}{r}7 \cdot 91 \\
3 \cdot 66 \\
13 \cdot 35\end{array}$ & $\begin{array}{l}- \\
0.00 \\
3 \cdot 49\end{array}$ & $\begin{array}{l}- \\
\text { NS } \\
<0.005\end{array}$ \\
\hline $\begin{array}{l}\text { a1-AT in } \mathrm{mg} \% \\
\text { MS } \\
\text { Normals } \\
\text { Pathological controls }\end{array}$ & $\begin{array}{l}135 \cdot 38 \\
217 \cdot 83 \\
206 \cdot 75\end{array}$ & $\begin{array}{l}69 \cdot 83 \\
40 \cdot 16 \\
70 \cdot 53\end{array}$ & $\begin{array}{r}\overline{32} \cdot 64 \\
4 \cdot 29\end{array}$ & $\begin{array}{l}- \\
<0.005 \\
<0.05\end{array}$ \\
\hline
\end{tabular}

Table 3 Mean SD and statistical variance analysis of the coagulation indices in the normal control group compared to the pathological control group

\begin{tabular}{|c|c|c|c|c|}
\hline & Mean & $S D$ & $F$ & $p$ \\
\hline $\begin{array}{l}\text { Plasminogen in } \mathrm{mg} \% \\
\text { Normals } \\
\text { Pathological controls }\end{array}$ & $\begin{array}{l}11 \cdot 57 \\
16 \cdot 61\end{array}$ & $\begin{array}{l}1 \cdot 75 \\
5 \cdot 31\end{array}$ & $\overline{21} \cdot 80$ & $-\overline{<0.005}$ \\
\hline $\begin{array}{l}\text { Fibrinogen in } \mathrm{mg} \% \\
\text { Normals } \\
\text { Pathological controls }\end{array}$ & $\begin{array}{l}342 \cdot 00 \\
431 \cdot 66\end{array}$ & $\begin{array}{l}49 \cdot 64 \\
53 \cdot 96\end{array}$ & $\overline{25} \cdot 29$ & $-\overline{<0} 005$ \\
\hline $\begin{array}{l}\text { AT III in mg } \% \\
\text { Normals } \\
\text { Pathological controls }\end{array}$ & $\begin{array}{l}28 \cdot 86 \\
34 \cdot 81\end{array}$ & $\begin{array}{r}3 \cdot 66 \\
13 \cdot 35\end{array}$ & $\overline{5} \cdot 21$ & $-\overline{<0.05}$ \\
\hline $\begin{array}{l}\alpha-1 \mathrm{AT} \text { in } \mathrm{mg} \% \\
\text { Normals } \\
\text { Pathological controls }\end{array}$ & $\begin{array}{l}217 \cdot 83 \\
206 \cdot 75\end{array}$ & $\begin{array}{l}40 \cdot 16 \\
70 \cdot 53\end{array}$ & $\overline{0} \cdot 11$ & $\overline{N S}$ \\
\hline
\end{tabular}

Table 4 Correlation coefficient $r$, $t$ and p obtained $b y$ comparing some of the tests used

\begin{tabular}{lllll}
\hline Correlation & $\begin{array}{l}\text { MS no } \\
\text { of cases }\end{array}$ & $r$ & $t$ & $p$ \\
\hline $\begin{array}{l}\text { Whole blood } \\
\text { viscosity/haematocrit }\end{array}$ & 36 & +0.79 & 7.47 & $<0.001$ \\
$\begin{array}{l}\text { Plasma viscosity/ } \\
\text { fibrinogen }\end{array}$ & 36 & -0.38 & 2.43 & $<0.02$ \\
$\begin{array}{l}\text { Plasma viscosity/ } \\
\text { plasma globulins }\end{array}$ & 35 & +0.36 & 2.21 & $<0.05$ \\
$\begin{array}{l}\text { Relative viscosity/ } \\
\text { haematocrit }\end{array}$ & 36 & +0.43 & 2.84 & $<0.01$ \\
$\begin{array}{l}\text { Fibrinogen/ } \\
\text { fibrinolysis }\end{array}$ & 36 & +0.03 & 0.15 & $\mathrm{NS}$ \\
$\begin{array}{l}\text { Plasminogen/ } \\
\text { fibrinolysis } \\
\begin{array}{l}\text { Plasminogen/ } \\
\text { fibrinogen }\end{array}\end{array}$ & 36 & +0.13 & 0.78 & $\mathrm{NS}$ \\
\hline
\end{tabular}

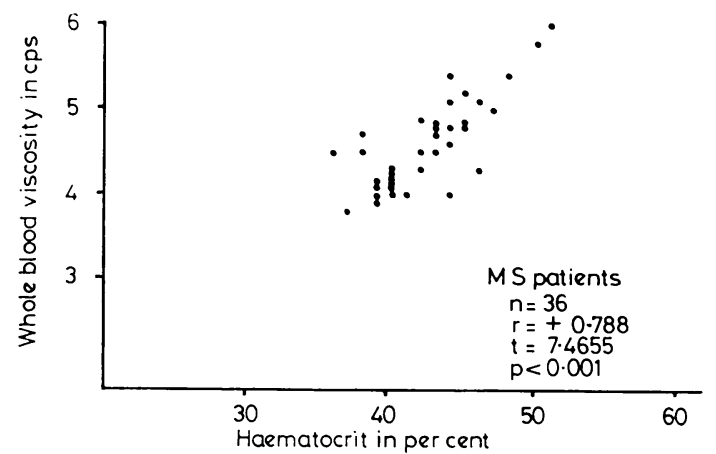

Fig 1 Correlation between whole blood viscosity (ordinate) and haematocrit (abscissa) in the MS patient group. 


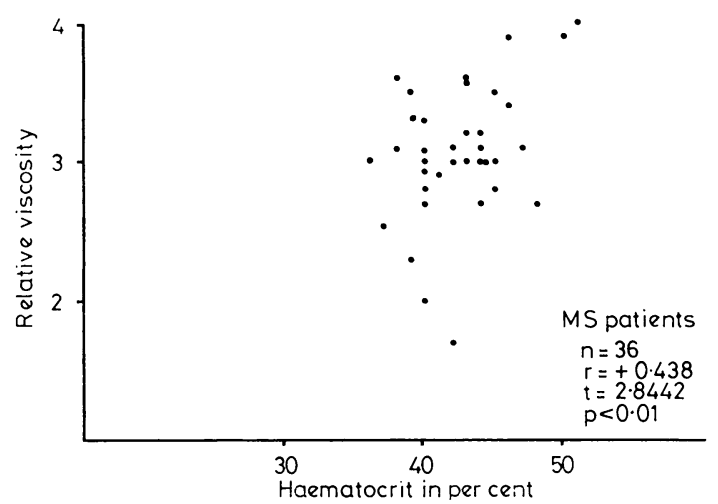

Fig 2 Correlation between relative viscosity (ordinate) and haematocrit (abscissa) in the patients with $M S$.

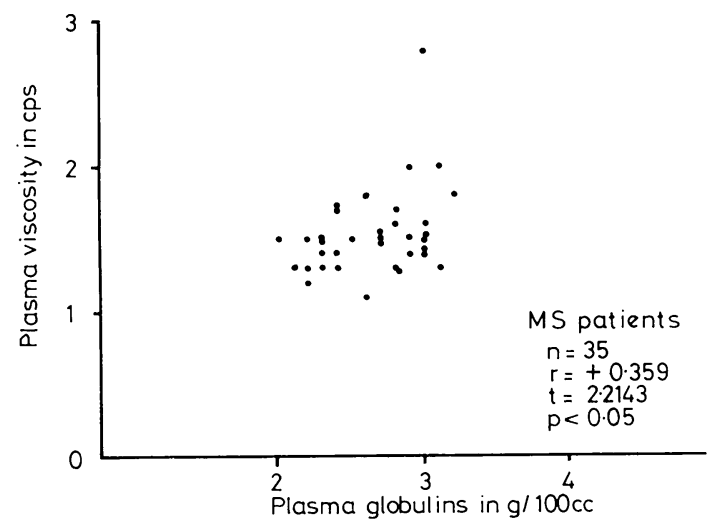

Fig 3 Plasma viscosity and plasma globulins correlation in the MS patient group.

\section{Results}

The results are summarised in tables $1-4$ and in figs 1-3. The difference of the means between the MS and the normal group was found to be statistically significant for whole blood viscosity, relative viscosity, fibrinogen, plasminogen and $\alpha 1-\mathrm{AT}$. An increase was found in the pathological control group compared to the MS group for the following tests: fibrinogen, plasminogen and a1-AT levels. An increase in the pathological control group compared to the normal group was seen for fibrinogen, plasminogen and AT III levels.

There were some correlations between the tests investigated. The whole blood viscosity and the relative viscosity correlated with the haematocrit values (figs 1 and 2). A negative correlation was seen between plasma viscosity and fibrinogen values $(\mathrm{r}=-0.38 ; t=2.43 ; \mathrm{p}=<0.025)$. Statistically sig- nificant correlations were also found between fibrinogen and plasminogen levels $(r=+0 \cdot 36$; $t=2.35 ; \mathrm{p}<0.05)$ and between plasma viscosity and globulin levels (fig 3 ).

\section{Discussion}

Our data confirm and amplify the abnormalities of the coagulative system reported in MS. Increased whole blood viscosity in MS has been reported, ${ }^{12}$ as well as increased fibrinolytic activity. ${ }^{3}$ The latter parameter was increased slightly in our cases, but this was not a significant difference from the normal controls. This may be due to differences in case selection. Our group was composed of inpatients with recent deterioration, on corticosteroid or adrenocorticotrophic therapy. Menon's patients were ambulant and not receiving treatment. Whole blood viscosity is known to be strongly influenced by the $\mathrm{Ht}$ values, and this appears to be true also for MS cases. However, while the $\mathrm{Ht}$ values were normal in the MS group, the blood viscosity was increased (that is, the viscosity increase is not only due to the Ht changes). Since fibrinogen is decreased and globulins are not particularly increased, such an increase of whole blood viscosity is probably due to an increase of relative viscosity, that is to decreased erythrocyte deformability. ${ }^{13}$ That this is so was demonstrated by the observation that relative viscosity was elevated in the patients as compared to controls. The alterations of the coagulative system in MS was confirmed also by the reduced levels of plasminogen, fibrinogen and $\alpha \mathrm{l}$-AT.

The observed alterations of the coagulative system may be related to the basic pathologica process in MS. The alterations observed in MS are concerned mainly with the immunological system. An increase of CSF IgG levels, of ten with oligoclonal bands, is extremely common. ${ }^{14}$ In the serum, reduction of complement factors, ${ }^{2}$ probable presence of immuno-complexes, ${ }^{15}$ and defective antibody production also have been described. ${ }^{16}$ In other immunological diseases characterised by the presence of antigen-antibody complexes, the coagulative system also is activated by an indirect mechanism. In SLE, for example, slight disseminated intravascular coagulation has been described. ${ }^{17}$ Related to this may be the observation that in MS there is increased platelet stickiness and platelet release. ${ }^{4}$

It is quite possible that in MS the immunological abnormalities would activate the coagulation cascade with fibrinogen consumption. Furthermore, the formation of fibrin will increase the fibrinolytic activity. As a consequence, as in classic disseminated intravascular coagulation, plasminogen also will be 
activated to plasmin with reduction of the plasminogen level. The plasmin, in turn, will react with the a1-AT which, with the a2-macroglobulin, is the most important antagonist and inhibitor of the plasmin. ${ }^{18}$

The coagulative indices in MS and other pathological controls were compound. In the latter group we observed an increase of plasminogen, fibrinogen and a1-AT compared to both MS and normal groups. Such divergent behaviour of some coagulation factors in MS and other non-immunological neurological diseases may be explained by the fact that the mean age of the pathological control group was substantially higher than the mean age of the MS and normal groups. It is known that with age there is an increase of several coagulation factors (fibrinogen and plasminogen, for instance). ${ }^{19}$ Furthermore, reduced mobility had probably affected both pathological groups in similar manner. Therefore, stasis and the prethrombotic state appeared to be of slight importance. In this regard it is important to note that no patient of the other pathological groups has ever shown clinical symptoms of thrombophlebitis or thrombotic state during the study.

Finally, we want to stress that all the observed abnormalities of the coagulation system can be explained on the basis of a chronic immunological disease. Therefore, such alterations are not necessarily involved in a direct way in the genesis of demyelination in MS plaques.

\section{References}

1 McAlpine D, Lumsden CE, Acheson ED. Multiple Sclerosis: a Reappraisal. Edinburgh: Churchill Livingstone, 1972.

2 Trouillas P, Betuel $\mathbf{H}$. Hypocomplementaemic and normocomplementaemic multiple sclerosis. $J$ Neurol Sci 1977 ; 32:425-35.

3 Menon IS, Dewar HA, Newell DJ. Fibrinolytic activity of venous blood of patients with multiple sclerosis. Neurology (Minneapolis) 1969; 19:101-5.

4 Caspary EA, Prineas J, Miller H, Field EJ. Platelet stickiness in multiple sclerosis. Lancet 1965; II :1 108-9

5 Dohnal K, Vagner B, Lupinek Z, Hule V. Notes on the influence of adrenocorticotrophic hormone on platelet stickiness in multiple sclerosis. J Neurol Sci $1971 ; 13 / 4: 443-8$.
6 Payling Wright $\mathrm{H}$, Thompson RHS, Zilkhe $\mathrm{KJ}$. Platelet adhesiveness in multiple sclerosis. Lancet 1965; II:1109-10.

7 Field EJ, Caspary EA. Behaviour of blood-platelets in multiple sclerosis. Some observations with a possible bearing on pathogenesis. Lancet 1964; II:876-80.

8 Allison RS, Millar JHD. Prevalence of disseminated sclerosis in Northern Ireland. Ulster Med J 1954; Suppl 2:1-27.

9 Wells RE, Denton R, Merrill EW. Measurement of viscosity of biologic fluid by cone-plate viscometer. $J$ Lab Clin Med 1961; 57:646-56.

10 Clifton EE, Cannamella DA. Fibrinolytic and proteolytic activity of human plasminogen prepared from fraction III of human plasma. J Appl Physiol 1953; 6:42-50.

11 Mancini G, Carbonara AO, Heremans JF. Immunochemical quantitation of antigens by single radial immunodiffusion. Immunochem 1965; 2:235-54.

12 Proewig F. Eine neue theorie zur Ursache der Multiplen Sklerose. Med Monatsschr 1958; 12 :732-4.

13 Girolami A, Patrassi GM, Bova G. No change of whole blood and plasma viscosity in cardiac patients after subcutaneous calcium heparin. Folia Haemat 1978; 105:391-9.

14 Lowenthal A. Restricted heterogeneity of the IgG in neurology. In: Karcher D, Lowenthal $A$, and Strosberg AD, eds. Humoral Immunity in Neurological Diseases. New York: Plenum Press 1979; 281-8.

15 Dumonde DG. The paradox of immunity and infection in multiple sclerosis. In: Clifford Rose, ed. Clinical Neuroimmunology. Oxford: Blackwell 1979; 275-98.

16 Davis LE, Hersh EM, Curtis JE et al. Immune status of patients with multiple sclerosis. Neurology (Minneap) 1972; 22:989-97.

17 Bowie EJW, Owen CA. The value of measuring platelet adhesiveness in the diagnosis of bleeding diseases. Am J Clin Path 1973; 60:302-8.

18 Heimburger N. Biochemistry of proteinase inhibitors from human plasma: a review of recent development. In: Fritz H, Tschesche H, Greene LJ, Truscheit E, eds. Proteinase Inhibitors. New York: Springer-Verlag $1974 ; 14$.

19 Meade TW, North WRS. Population-based distribution of haemostatic variables. Br Med Bull 1977; 33:283-8. 